\title{
A Formação Água Clara na Região de Araçaíba - SP: Registro U-Pb de Uma Bacia Mesoproterozóica
}

\author{
Werner Weber ${ }^{1}$ (wweber@ufpr.br), O swaldo Siga Júnior², Kei Sato ${ }^{3}$, José Manoel dos Reis N eto ${ }^{1}$, \\ Miguel Angelo Stipp Basei², Allen P. Nutman ${ }^{4}$ \\ ${ }^{1}$ Departamento de Geologia - Setor de Ciências da Terra - UFPR \\ Caixa Postal 19.001, CEP 81531-990, Curitiba, PR, BRA \\ 2Departamento de Mineralogia e G eotectônica - Instituto de Geociências - USP, São Paulo, SP, BRA \\ ${ }^{3}$ Centro de Pesquisas G eocronológicas - Instituto de G eociências - USP, São Paulo, SP, BRA \\ ${ }^{4}$ Research School of Earth Sciences - Australian National University, Canberra, AUS
}

Palavras-chave: Araçaíba, Formação Água Clara, metabásica, Mesoproterozóico, U-Pb.

\section{RESUMO}

O objetivo deste trabalho fundamenta-se no estudo isotópico dos corpos metabasíticos associados à Formação Água Clara e as suas relações com as encaixantes. A Formação Água Clara é constituída predominantemente por uma seqüência de rochas carbonáticas (mármores puros a impuros). Rochas cálcio-silicáticas, cálcio xistos, mica xistos, anfibólio xistos, quartzitos, granada-clorita-biotita xistos, metacherts, metatufos básicos e intermediários, metabasitos, anfibolitos e cornubianitos. As rochas metabásicas estudadas normalmente têm dimensões longitudinais expressivas chegando a quilométricas, com dimensões transversais de até centenas de metros. São de coloração cinza - esverdeada, apresentam granulometria fina a média e textura normalmente nematoblástica. Ocorrem termos mais isótropos que exibem textura granoblástica. São compostos por piroxênios (diopsídio ou augita), anfibólios (actinolita e hornblenda) e plagioclásios (andesina/oligoclásio). Os acessórios mais comuns são apatita, magnetita, epidoto, titanita e raramente zircão. Em lâmina observa-se texturas ofíticas e subofíticas preservadas o que indica uma provável origem ígnea para esses corpos. Os dados geoquímicos sugerem composições semelhantes a basaltos enriquecidos de cadeias mesoceânicas (E-MORB) com tendências a basaltos de ilhas oceânicas (OIB). As características de basaltos toleíticos, subalcalinos semelhantes a basaltos enriquecidos de cadeias mesoceânicas com tendência a basaltos de ilhas oceânicas (OIB), permitem sugerir como ambiente geotectônico gerador deste magmatismo básico, ambientes distensivos ou em bacias de retroarco. Os dados analíticos U-Pb (convencional, EMF e SHRIMP) obtidos para os litotipos metabásicos indicam épocas de cristalização dos zircões e conseqüiente formação dessas rochas durante o mesoproterozóico, com idades do intervalo 1590 - 1470 Ma. Os valores neoproterozóicos obtidos ( 600 Ma) provavelmente referem-se a processos de recristalização e neoformação de zircões nas rochas metabásicas, colocação de rochas de natureza granítica e resfriamento regional da Formação Água Clara.

Keywords: Água Clara Formations, Araçaíba, metabasic rocks, Mesoproterozoic, U-Pb.

\section{ABSTRACT}

The main objective of this work is to present $\mathrm{U}-\mathrm{Pb}$ isotopic data obtained from zircons of metabasic rocks and subordinate acid and associated rocks of the Água Clara Formation in the Araçaíba region - São Paulo. The Água Clara Formation is predominantly constituted by a sequence of carbonate rocks (pure to impure marbles), calc-silicate rocks, calc schists, mica schists, amphibole schists, quartzites, garnet-chlorite-biotite schists, metacherts, basic and intermediate metatuffs, metabasites, amphibolites and cornubianites. The metabasic bodies are usually a few km long with widths of hundreds of $\mathrm{m}$. They are greenish gray, fine- to medium-grained, and usually present nematoblastic texture. More isotropic terms also occur, showing granoblastic texture. They are composed of pyroxenes (diopside or augite), amphiboles (actinolite and hornblende), and plagioclases (andesine/oligoclase). The most common accessories are apatite, magnetite, epidote, titanite, and rare zircon. In thin section, preserved ophitic and subophitic textures are observed, indicating a probable igneous origin. The geochemical data suggest compositions similar to enriched midoceanic ridge basalts (E-MORB) tending to oceanic island basalts (OIB). The subalkaline, tholeiitic characteristics, similar to E-MOR basalts tending to OI basalts, suggest distension or back-arc 
environments as the geotectonic settings for the basic magmatism. The geochronologic and geochemical characteristics and structural patterns described for the Água Clara Formation metabasic lithotypes (probably sills and/or dikes) suggest that periodic volcanism with associated sedimentation occurred during the Mesoproterozoic at about $1500 \mathrm{Ma}$. This event represents an important marker in the volcano-sedimentary evolution of the Apiaí Domain. The Neoproterozoic values obtained refer to zircon recrystallization, to neoformation processes which affected the metabasics and amphibolites, to the emplacement of granitic and acid volcanic rocks, and to regional cooling of the Água Clara Formation.

\section{IN TRO DUÇÃO}

O estabelecimento de uma cronologia nos terrenos précambrianos, do Leste Paranaense e Sudeste de São Paulo tem se mostrado problemático, função principalmente da dificuldade na obtenção de dados geocronológicos precisos em seqüências metavulcano-sedimentares de baixo a médio grau metamórfico. Idades relacionadas à deposição e metamorfismo destas seqüências metavulcano-sedimentares representam uma importante contribuição ao quadro geológico deste setor.

$\mathrm{O}$ estudo isotópico $\mathrm{U}-\mathrm{Pb}$ em zircões dos litotipos metabásicos intercalados às sequiências metassedimentares, constitui uma importante ferramenta no posicionamento estratigráfico dessas unidades pré-cambrianas.

Este trabalho tem como principal objetivo apresentar dados isotópicos U-Pb em zircões de rochas metabásicas, e subordinadamente ácidas e associadas à Formação Água Clara que afloram próximos a Araçaíba no estado de São Paulo, pela existência de boas exposições dessas rochas (Figura 1). Estes corpos metabasíticos ocorrem intercalados a metacalcarenitos, metacalcáreos micríticos, metassiltitos, calcoxistos, quartzitos que se mostram intrudidos por granitos quartzo-feldspáticos deformados.

\section{TRABALHOS ANTERIORES}

Os trabalhos do pré-cambriano paranaense e sudeste paulista foram motivados desde cedo devido aos importantes jazimentos minerais encontrados na região. Os trabalhos realizados durante a segunda metade do século XIX até meados da década de 50, envolveram principalmente o reconhecimento geológico destes terrenos.

A primeira tentativa em situar a Formação Água Clara numa coluna estratigráfica foi efetuada por Marini et al. (1967) que na mesma oportunidade redenominaram a Série Açungui para Grupo Açungui. Os autores verificaram que as litologias desta unidade repousam em aparente discordância sobre a formação Votuverava, a partir de relações estruturais. Desta forma os autores posicionaram as litologias desta unidade no topo do Grupo Açungui.

Fuck et al. (1971) reforçam as correlações entre as formações Capiru e Itaiacoca, colocando-as lado a lado; mantém a Formação Água Clara no topo do Grupo Açungui e considerando como embasamento a Formação Setuva.

Veiga e Salomão (1980) e Piekarz (1981) descreveram a Formação São Sebastião e a seqüência Perau, respectivamente, com características litológicas, estruturais e metamórficas, semelhantes àquelas observadas na Formação Água Clara por Pontes $(1981,1982)$.

Fritzsons et al. (1982) retiram a Formação Água Clara da base do Grupo Açungui situando-a no topo do Grupo Setuva sem, contudo, esclarecer os critérios utilizados para tal modificação e atribuindo idade Mesoproterozóica para a mesma.

Pontes $(1981,1982)$ posiciona a Formação Água Clara na base do Grupo Açungui ao identificar metassedimentos típicos de águas profundas, com metamorfismo xisto verde alto início do grau médio, a ocorrência de dobras isoclinais quase sempre rompidas, interpretado como incremento na intensidade de deformação e metamorfismo em relação às Formações Capirú e Votuverava. Estas características levaram o autor a sugerir para a Formação Água Clara, deposição em ciclo tectônico anterior, provavelmente do Proterozóico médio.

Os principais estudos relacionados aos terrenos metavulcano-sedimentares do Grupo Açungui, envolvendo mapeamento geológico, análises faciológicas e estruturais e modelamento tectônico, referem-se a Fiori e colaboradores (que publicaram mais de uma dezena de trabalhos na década de 80, sintetizados e revisados em Fiori, (1990, 1992), Fiori e Gaspar (1993) e aos trabalhos desenvolvidos por Campanha et al. (1987) e Soares (1987).

Almeida (1989) e Almeida et al. (1986), descrevem na região de Araçaíba - SP, rochas carbonáticas constituídas por cálcio-silicáticas, cálcio-xistos, mármores impuros, metabasitos e quartzitos, que sofreram três fases deformacionais. Almeida (1989) considera o Proterozóico inferior como idade de deposição da referida formação.

Também na região de Araçaíba - SP, Frascá et al. (1990) sugerem três tipos de magmatismo básico durante períodos tectônicos; um de natureza toleítica de estágio inicial de abertura de bacia ou ao início de fechamento; o segundo, basaltos shoshoníticos de margem continental ativa (estágio final de fechamento da bacia) e o terceiro um magmatismo básico toleítico de natureza continental.

A existência de diversas e distintas colunas estratigráficas desses terrenos metavulcano-sedimentares caracteriza a dificuldade no posicionamento das unidades 

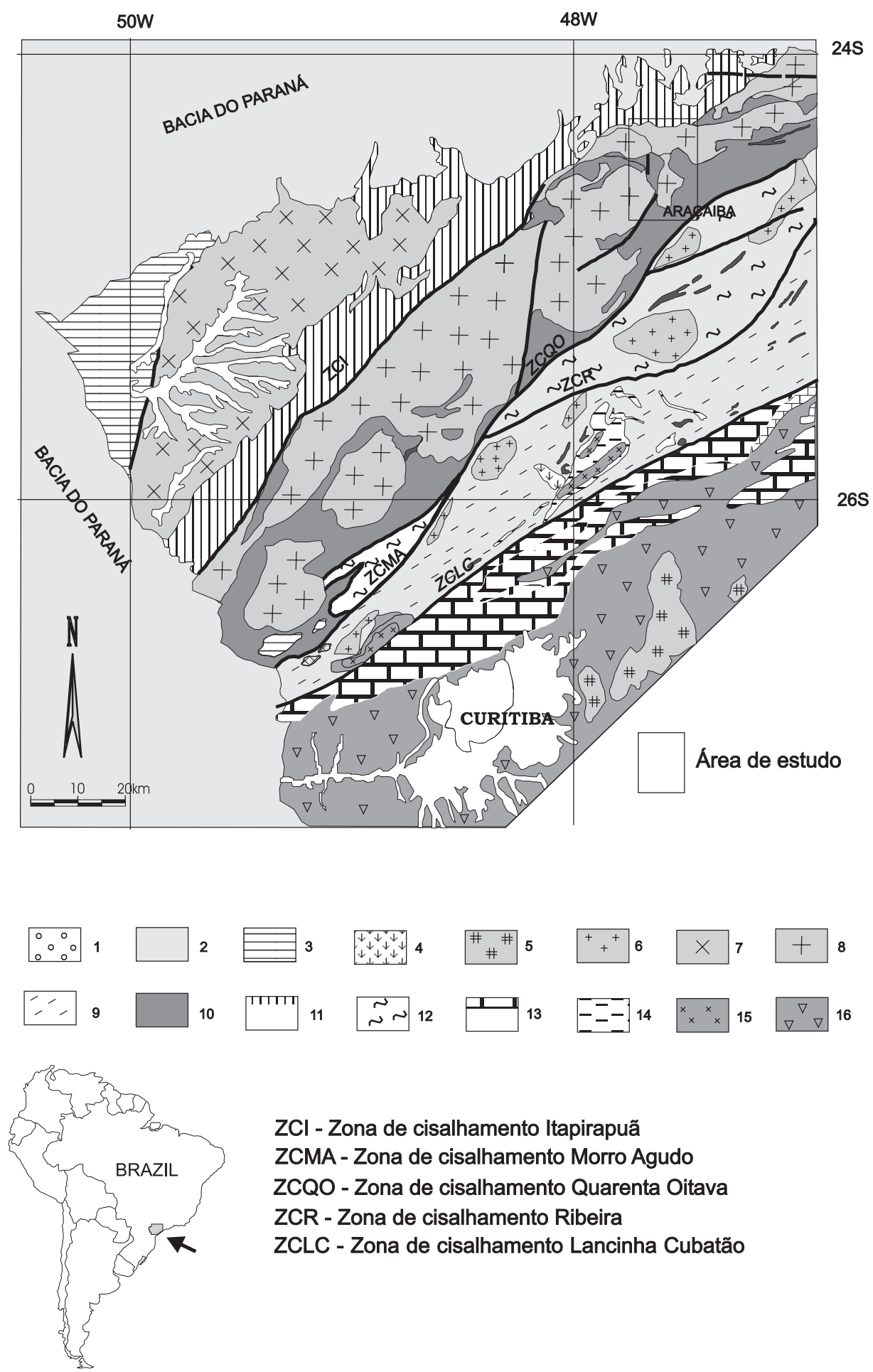

$\mathrm{ZCl}$ - Zona de cisalhamento Itapirapuã

ZCMA - Zona de cisalhamento Morro Agudo

ZCQO - Zona de cisalhamento Quarenta Oitava

ZCR - Zona de cisalhamento Ribeira

ZCLC - Zona de cisalhamento Lancinha Cubatão

Figura 1. Esquema geológico com as principais unidades geológicas e tectônicas, sudeste brasileiro. 1. Cobertura quaternária. 2. Bacia do Paraná. 3. Bacias de Ante-País (G rupo Castro (NW) e Grupo Camarinha (SW)). 4. Sienito Tunas. 5. Complexo batolítico costeiro. 6. Granitóides sin- a pós-colisionais. 7. Batólito Cunhaporanga. 8. Batólito Três Córregos e corpos graníticos associados. 9. Formação Votuverava. 10. Formação Água Clara. 11. G rupo Itaiacoca. 12. Seqüências Lajeado e Antinha. 13. Formação Capirú. 14. Seqüências Perau e Betara. 15. Granitóides alcalinos deformados e granitóides cálcio-alcalinos deformados. 16. Complexo G náissico-Migmatítico Atuba. 
geológicas em termos estratigráficos e tectônicos. O trabalho de Fassbinder (1996), mostra a existência de cerca de 40 colunas geológicas sugeridas (notadamente para o Grupo Açungui), várias das quais bastante discrepantes, e posiciona a Formação Água Clara na base do Grupo Açungui, em função do metamorfismo e deformação mais intenso que as demais formações (Votuverava, Capirú/ Itaiacoca).

Os inúmeros trabalhos setorizados no âmbito do Grupo Açungui, contribuíram não só para a proliferação da nomenclatura, como também do variado empilhamento estratigráfico. No âmbito regional, merecem destaque os trabalhos de Hasui (1986), Soares (1987), Campanha et al. (1987), Fiori (1990, 1992), Fiori e Gaspar (1993), Spoladore (1993), Reis Neto (1994), Soares e Rostirolla (1997), Hackspacher et al. (1997, 2000), Wernick (1997) e Campanha e Sadowski (1999), que abordam de modo integrado estudos relacionados a ambientes de sedimentação, metamorfismo, magmatismo (incluindo plutonismo e vulcanismo), caracterização estrutural, geofísica, geocronológica, compartimentação tectônica, entre outros.

Reis Neto (1994) apresenta idades isocrônicas $\mathrm{Pb}-\mathrm{Pb}$ e $\mathrm{Rb}$-Sr de metavulcânicas $(\sim 1250 \mathrm{Ma})$, de mármores ( 1120 Ma) e metadoleritos ( 1080 Ma) do Grupo Itaiacoca e para rochas anfibolíticas ( 1080 Ma) da Formação Água Clara. Interpreta tais valores como relacionados à época de sedimentação/vulcanismo associado à formação dessas duas bacias.

Maniesi (1997) apresenta idades K-Ar em concentrado de anfibólio de rochas anfibolíticas de Adrianópolis - PR $(675 \pm 21 \mathrm{Ma})$ e de plagioclásios de metabásicas da mesma região ( $1456 \pm 25 \mathrm{Ma}$ ), neste caso em cristais admitidos pelo autor como preservados do metamorfismo. Apresenta ainda um valor K-Ar em anfibólio de $881 \pm 46$ Ma, obtido em anfibolitos da região de Campo Largo.

Estudos utilizando-se de isótopos estáveis $\left(\mathrm{O}^{18}\right)$ realizados por Fassbinder (1996), sugerem para a Formação Água Clara idades mais jovens que 1,3 Ga, para a Formação Votuverava idades próximas a 0,9 Ga e para a Formação Capirú/Itaiacoca idades mais antigas que $0,7 \mathrm{Ga}$.

\section{GEOLOGIA DA ÁREA}

As seqüências metavulcano-sedimentares pertencentes à Formação Água Clara, distribui-se em dois compartimentos principais, o primeiro no sudeste Paranaense e o segundo no sul-sudeste de São Paulo. O primeiro compartimento localiza-se nas proximidades de Rio Branco do Sul, onde as rochas da Formação Água Clara encontram-se balizadas a NNW pelo batólito Granítico Três Córregos, que se mostra intrusivo nas seqüências metavulco-sedimentares. A SSE o limite é tectônico, balizado pela zona de cisalhamento Mor- ro Agudo. No segundo compartimento essas rochas distribuem-se a NNE da localidade de Apiaí/Araçaíba, sendo limitado a SSE através de zona de cisalhamento com as sequiências pertencentes ao Subgrupo Lajeado e correlatos. A NNW é balizada pelo Batólito Granítico Três Córregos.

A Formação Água Clara é constituída predominantemente por uma sequiência carbonática impura. Inclui mármores puros a impuros, calciossilicatadas, cálcio xistos, mica xistos, anfibólio xistos, quartzitos, granada-clorita-biotita xistos, metacherts, metatufos básicos e intermediários, metabasitos, anfibolitos e cornubianitos. Trata-se de litotipos sugestivos de ambiente plataformal relativamente profundo. Os corpos de rochas anfibolíticas e metabásicas que ocorrem em meio às seqüências metavulcano-sedimentares apresentam, de um modo geral, expressivas dimensões longitudinais quando comparadas às dimensões laterais, estas normalmente decamétricas.

As relações de contato dos litotipos metabásicos dificilmente são observadas e, quando presentes, mostram contatos concordantes e bruscos com a estruturação das rochas encaixantes. Constituem corpos que se mostram, por vezes, totalmente anfibolitizados (anfibolitos) e por outros, pouco modificados pelo metamorfismo (metabásicas), coerentes com o padrão metamórfico das seqüências metassedimentares encaixantes. Apresentam-se normalmente intemperizadas, adquirindo cor verde escura a cinza esverdeada e granulação fina a fina-média, raramente grossa. Os termos anfibolíticos apresentam texturas granoblásticas a granonematoblásticas, predominando em termos mineralógicos o anfibólio (hornblenda - actinolita), geralmente alterado para biotita e/ou clorita, o plagioclásio (albitaoligoclásio), normalmente saussuritizado, e em maior ou menor proporção, quartzo, biotita, clorita, sericita, granada, diopsídio, titanita, opacos, epidoto e carbonato. Os termos metabásicos normalmente apresentam características ígneas reliquiares, como por exemplo, texturas ofíticas a subofíticas, e mineralogia composta por clinopiroxênios, plagioclásio cálcico, geralmente oligoclásio-andesina podendo ocorrer labradorita, hornblenda, quartzo, sericita, carbonato, apatita, titanita, epidoto e opacos.

O grau metamorfismo nessas rochas chegou a facies anfibolito. A paragênese que melhor caracteriza o grau metamórfico que atuou sobre as rochas metabasíticas pode ser sumarizado pela seguinte reação: hornblenda + plagioclásio (oligoclásio/andesina - em alguns casos labradorita) + diopsídio + titanita que indica grau facies anfibolito (Winkler, 1977). Processos de retrometamorfismo podem ser caracterizados através da saussuritização em plagioclásios e alterações em anfibólios e piroxênios formando epidoto, clorita e actinolita. Este retrometamorfismo não deve ter ultrapassado a facies xisto verde. Sobreposto a esse metamorfismo ocorre metamorfismo de contato originado pela 
colocação de corpos granitóides do Complexo Três Córregos gerando cornubianitos e hornfels.

Pode-se citar ainda um evento retrometamórfico, evidenciado pela saussuritização de feldspatos, epidotização de actinolita e cloritização de hornblendas. Este evento de retrometamorfismo não chegou a ultrapassar as condições da facies xisto verde.

O padrão estrutural observado na região é uma foliação (Sc) de baixo ângulo, paralela à subparalela ao bandamento composicional das rochas cálcio-silicáticas. A questão é se esta foliação representa uma superfície $\mathrm{Sn}$ ou $\mathrm{Sn}+1$, em função da existência de dobras centimétricas fechadas a isoclinais em bainha desenhadas pelo Sn (?) com flancos rompidos. Esta superfície mostra-se afetada por uma foliação de cisalhamento rúptil-dúctil heterogeneamente desenvolvida de baixo a médio ângulo, que muitas vezes confundese com a anterior. Deformações posteriores são responsáveis por dobramentos mais abertos, com eixos normalmente subhorizontais (NE-SW) e seus planos axiais subverticalizados. Sistemas transcorrentes são responsáveis por uma foliação Sc de alto ângulo, que oblitera completamente as feições anteriores. Tal padrão mostra-se de um modo geral, muito similar ao observado por Almeida (1986) e Fiori (1990).

Estudos litogeoquímicos realizados nas rochas metabásicas pertencentes à Formação Água Clara, sugerem para estas rochas, origem ortoderivada de natureza toleítica subalcalina, representando basaltos de fundo oceânico transicionais (T-MORB) ou basaltos de arco de ilha (OIB) Weber et al. (2002) fato este já levantado por Frascá et al. (1990, 1997), Maniese (1997) e Maniese e Oliveira (1999).

\section{ESTUDO GEOCRONOLÓGICO}

$\mathrm{O}$ estudo geocronológico U-Pb (zircões) envolveu rochas metabásicas da região de Araçaíba - SP intercaladas nas seqüências metavulcano-sedimentares da Formação Água Clara (Figura 1).

Os litotipos metabásicos analisados apresentam geralmente granulação fina a média, e se mostram em campo incipientemente deformadas, com padrão estrutural similar ao observado nas seqüências metassedimentares encaixantes. Ao microscópio a superfície principal (Sn) é caracterizada pela orientação de cristais de anfibólio e plagioclásios.

Os zircões de rocha metabásicas nem sempre têm a forma característica: prismático, alongado e biterminado, mas na maioria dos casos são mal formados, às vezes não tendo uma forma definida.

As análises isotópicas U-Pb foram realizadas no CPGeo - USP (método convencional e evaporação de monocristal em filamento EMF) e nos laboratórios da Austrália (SHRIMP) através da cooperação científica com o Dr. Allen P. Nutman, neste caso, envolvendo estudos de catodoluminescência.

$\mathrm{O}$ estudo isotópico $\mathrm{U}-\mathrm{Pb}$ em zircões, relativo às rochas metabásicas de número de campo WWD-03, envolveu as três técnicas analíticas mencionadas (convencional, EMFe SHRIMP). Inicialmente as populações de zircões foram selecionadas através da técnica split, utilizando-se do separador eletromagnético tipo FRANTZ, para posterior catação manual em lupa binocular.

As populações de zircões foram selecionadas em função das diferenças relacionados ao hábito (prismas relativamente bem formados, ovalados, com terminações difusas), normalmente translúcidos, podendo apresentar fraturas e inclusões.

Os dados analíticos SHRIMP, relativos a cinco zircões estudados (bordas e núcleos) alinharam-se em diagrama Tera-Wasserbourg (Figura 2), caracterizando para o intercepto superior idades de $1593 \pm 70 \mathrm{Ma}$ e para o intercepto inferior de $586 \pm 24 \mathrm{Ma}$. Dois dos dados analíticos plotam no diagrama em posições intermediárias entre os valores mencionados.

As imagens de catodoluminescência revelam sobrecrescimentos em praticamente todos os zircões analisados. $\mathrm{O}$ ponto mais próximo ao intercepto superior (idade mais antiga) refere-se à uma análise de uma porção mais interna preservada de sobrecrescimento, enquanto nos demais as análises referem-se a porções mais externas, caracterizadas por sobrecrescimentos e zonas oscilatórias. Os dados apresentados sugerem para a época de cristalização dos zircões o Mesoproterozóico, com idade de $1593 \pm 70$ Ma. Os valores relativos ao Neoproterozóico (586 $\pm 24 \mathrm{Ma})$ referem-se às zonas de sobrecrescimento desses zircões, indicativas provavelmente de processos metamórficos, bem como relacionados à colocação do batólito Granítico Três Córregos.

Os dados isotópicos obtidos através da técnica convencional em quatro populações da mesma amostra WWD-03, alinham-se ao longo da discórdia, interceptando a curva concórdia em $1561 \pm 18 \mathrm{Ma}$ (intercepto superior), e $751 \pm 15 \mathrm{Ma}$ (intercepto inferior). O posicionamento intermediário de três pontos analíticos na discórdia (Figura 3), revela perdas parciais de $\mathrm{Pb}$, provavelmente associadas à tectônica Neoproterozóica. O único ponto posicionado próximo ao intercepto inferior localiza-se à esquerda da curva concórdia, denotando desequilíbrio isotópico, possivelmente relacionado à digestão incompleta dos zircões analisados. Portanto, a idade obtida neste intercepto de $751 \pm$ 15 Ma deve ser encarada com ressalvas, provavelmente sem significado geológico. De qualquer modo, trata-se de zircões cristalizados no Mesoproterozóico, com idade de $1561 \pm$ $18 \mathrm{Ma}$, com perda de $\mathrm{Pb}$ associadas à tectônica Neoproterozóica impressa nesses litotipos. 


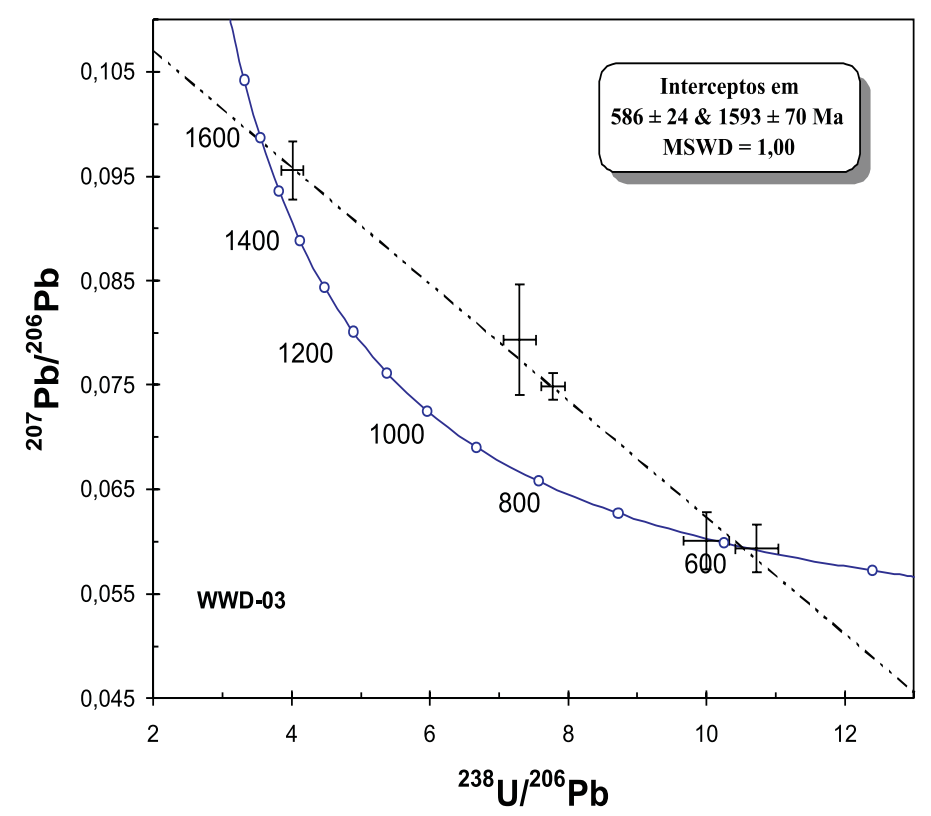

A

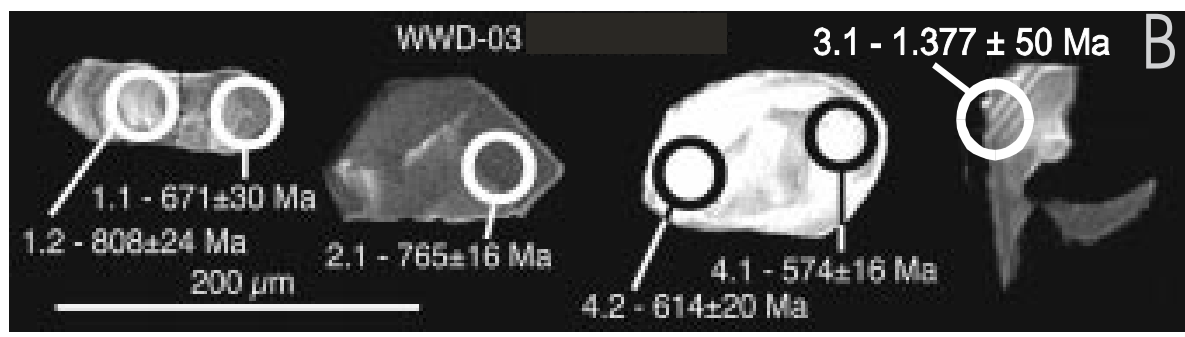

Figura 2. A - Diagrama Tera-Wasserbourg. B - Imagens de catodoluminescência dos zircões da amostra WWD-03.

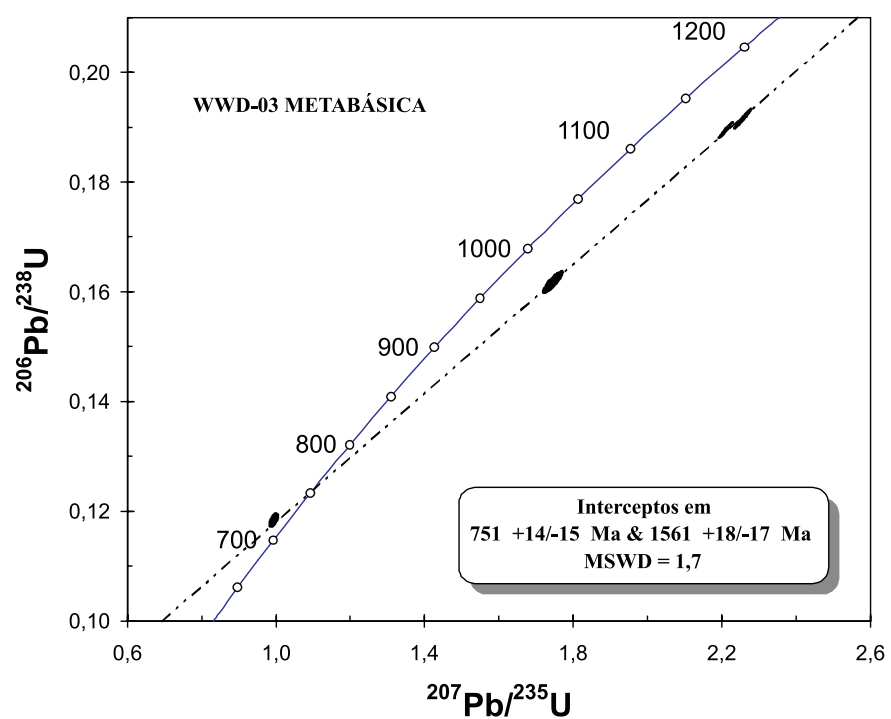

Figura 3. Diagrama Concórdia para quatro frações da amostra WWD-03. 
Utilizando-se a técnica EMF (evaporação de monocristal em filamento) em zircão dessa mesma amostra (WWD-03) observa-se um patamar com idades ao redor de $1461 \pm$ $51 \mathrm{Ma}$ (Figura 4), caracterizando mais uma vez épocas de cristalização relacionadas ao Mesoproterozóico. Acrescente-se que tal técnica, nesses casos não é efetiva para análise das bordas dos zircões, função da quantidade de $\mathrm{Pb}$ comum presente e queima relativamente rápida desta borda.

Outros afloramentos estudados da região de Araçaíba referem-se às rochas metabásicas que ocorrem nos arredores de Taquari-Mirim (números de campo WWD-32 e WWD-33).

Na amostra WWD-32, foram realizadas análises em quatro frações de zircões, utilizando-se a técnica convencional. Duas frações 32a e 32d são compostas por zircões mal for-

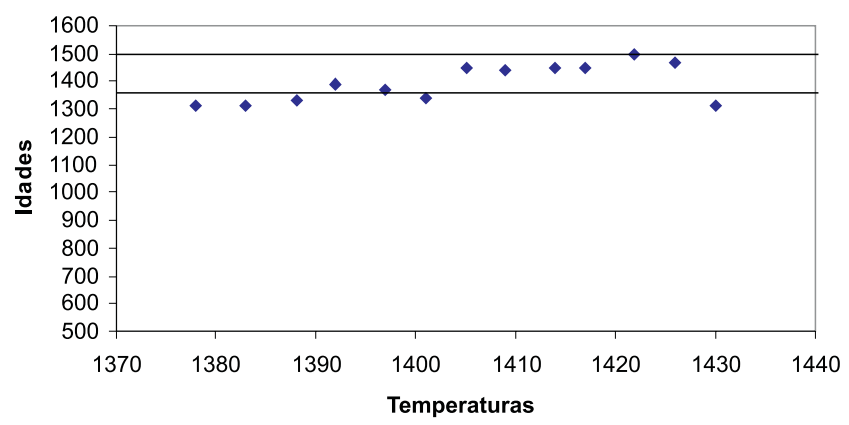

mados com arestas indefinidas, translúcidos e livres de inclusões e fraturas. Em diagrama concórdia estes dois pontos analíticos posicionaram-se no intercepto superior. As outras duas frações, 32b e 32c são compostos por zircões prismáticos, relativamente bem formados, com arestas definidas, transparentes, incolores e geralmente com inclusões e/ou fraturas. Essas duas frações, 32b e 32c distinguem-se apenas pelo tamanho do prisma, sendo o primeiro mais curto (2:1) e o segundo ( 3:1). Estes dois pontos posicionaramse, no intercepto inferior, praticamente sobre a curva concórdia. A discórdia que melhor se ajusta a esses pontos analíticos, revelou para o intercepto superior idade de $1484 \pm$ $76 \mathrm{Ma}$ e para o inferior de $601 \pm 83 \mathrm{Ma}$. Trata-se de zircões cristalizados no Mesoproterozóico e recristalizados parcialmente ou neoformados no Neoproterozóico (Figura 5).

Figura 4. Gráfico Idade versus Temperatura para análises por evaporação de monocristal em filamento.
Figura 5. Diagrama Concórdia para quatro frações da amostra de campo número WWD-32 e suas respectivas tipologias.
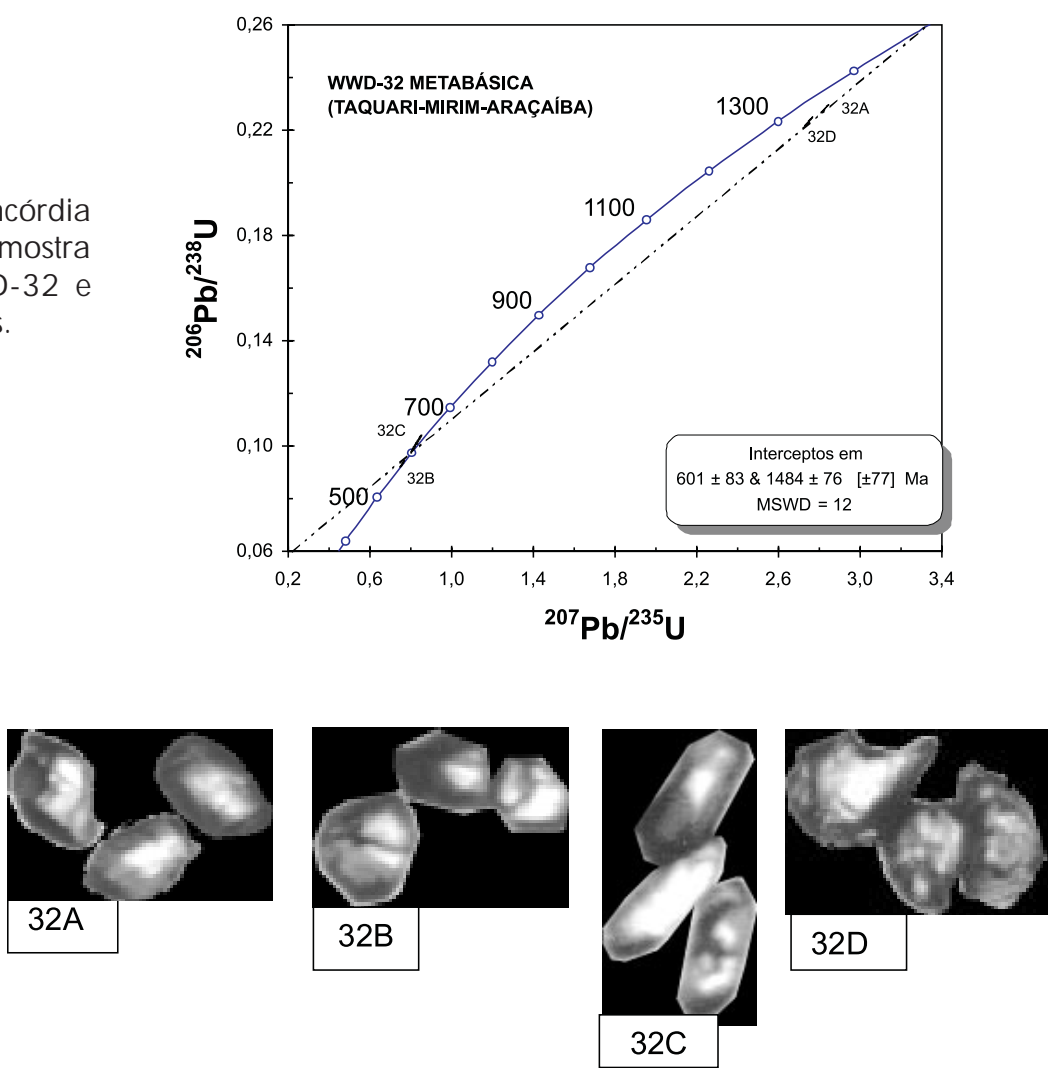
Na amostra com número de campo WWD-33, relativamente próxima ao afloramento WWD-32, os zircões são raros, possibilitando apenas a concentração de duas frações. Tentativamente esses pontos analíticos foram lançados em diagrama concórdia conjuntamente com os outros pontos das amostras WWD-3 e 32, (Figura 6).A discórdia que melhor se ajusta a esses pontos analíticos intercepta a curva concórdia em $1477 \pm 46 \mathrm{Ma}$ (superior) e $575 \pm 46 \mathrm{Ma}$ (inferior), valores estes muito similares e mais precisos que os anteriores discutidos.

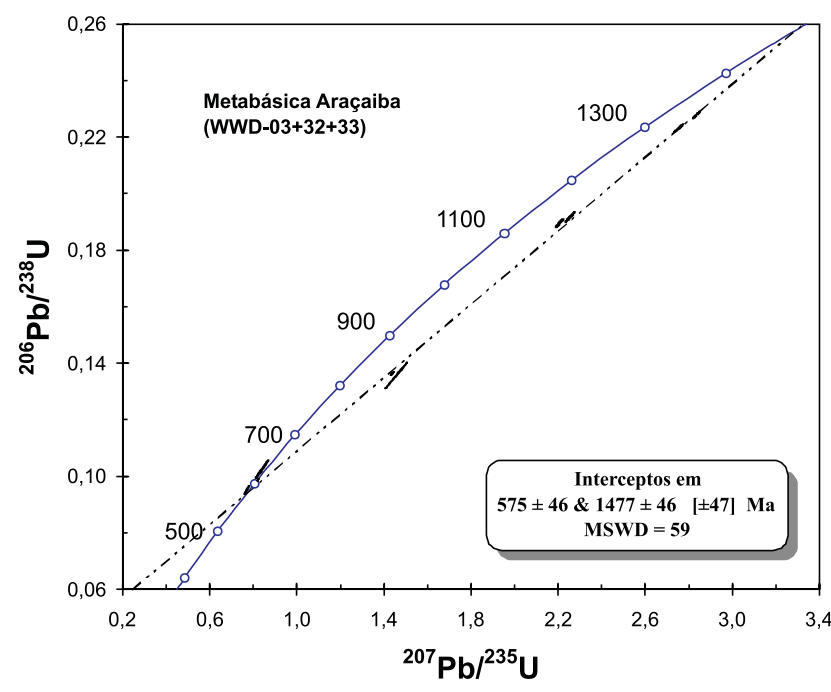

Figura 6. Diagrama Concórdia com as frações das amostras com número de campo WWD-03+32+33.

\section{CONSIDERAÇÕES FINAIS}

O estudo geológico - geocronológico, envolvendo principalmente análises $\mathrm{U}-\mathrm{Pb}$ em zircões de rochas metabásicas intercaladas nas seqüências metavulcanosedimentares da Formação Água Clara permite tecer as seguintes considerações:

a. os dados analíticos U-Pb (convencional, EMF e SHRIMP) obtidos para os litotipos metabásicos indicam épocas de cristalização dos zircões e conseqüente formação dessas rochas durante o Mesoproterozóico, com idades do intervalo 1590 - $1470 \mathrm{Ma}$;

b. os estudos de catodoluminescência realizados em zircões de rocha metabásica revelam a presença de núcleos cristalizados no Mesoproterozóico e de zonas de sobrecrescimento de amplitudes variáveis, com idades mais significativas no intervalo $600-580 \mathrm{Ma}$; c. a estruturação desses terrenos (similar ao das seqüências metavulcano-sedimentares encaixantes) relaciona-se ao Neoproterozóico, quando do metamorfismo de grau médio (facies anfibolito). Dados $\mathrm{K}-\mathrm{Ar}$ em minerais metamórficos realizados por diferentes autores, bem como $\mathrm{U}-\mathrm{Pb}$ em zonas de sobrecrescimento dos zircões revelam a importância do Neoproterozóico no arcabouço geotectônico desses terrenos;

d. os dados $\mathrm{U}-\mathrm{Pb}$ (zircões) obtidos em rochas metabásicas e anfibolíticas das seqüências Perau e Votuverava apresentam idades relacionadas também ao Mesoproterozóico, 1480 Ma (Basei, informação verbal), similares às observadas para Formação Água Clara.

\section{CONCLUSÃO}

As características geocronológicas, geoquímicas e padrões estruturais descritos para os litotipos metabásicos da Formação Água Clara sugerem épocas de vulcanismo com sedimentação associada, relacionada ao Mesoproterozóico, com idades próximas aos $1500 \mathrm{Ma}$. Os valores Neoproterozóicos ( \pm 600 Ma.) obtidos, referem-se a processos de recristalização e neoformação de zircões (metabásicas/anfibolitos), colocação de rochas de natureza granítica/vulcânicas ácidas e resfriamento regional da Formação Água Clara.

\section{AGRADECIMENTOS}

Os autores agradecem ao suporte financeiro do projeto FAPESP No 99/04040-8, que permitiu o presente estudo e ao CNPq pelo auxílio bolsa, processo 140833/1999-4.

\section{REFERÊNCIAS BIBLIOGRÁFICAS}

ALMEIDA, M. A. Geologia da formação Água Clara na região de Araçaíba - SP. 1989. 184 f. Dissertação (Mestrado). Instituto de Geociências, Universidade de São Paulo, São Paulo.

ALMEIDA, M. A.; BISTRICHI, C. A.; STEIN, D. P. AFormação Água Clara na região de Araçaíba, Estado de São Paulo: litotipos, metamorfismo e deformação. In: CONGRESSOBRASILEIRODEGEOLOGIA, 35., 1986. Goiânia. Anais... Goiânia: SBG, 1986. v. 2, p. 905-918.

CAMPANHA, G. A. C. Tectônica proterozóica do Alto e Médio Vale do Ribeira, estados de São Paulo e Paraná. 1991. 296 f. Tese (Doutorado) - Instituto de Geociências, Universidade de São Paulo, São Paulo.

CAMPANHA, G. A. C.; BISTRICHI, C. A.; ALMEIDA, M.A. Considerações sobre a organização litoestratigráfica e evolução tectônica da faixa de dobramentos Apiaí. In: III SIMPÓSIO SUL BRASILEIRO DE GEOLOGIA, 1987. 
Curitiba. Atas... Curitiba: 1987, v. 2, p. 725-742.

CAMPANHA, G.A. C.; SADOWSKI, G. R. Cinturão Ribeira: tectônica e questões pendentes sobre a sua evolução. In:CONGRESSOBRASILEIRODEGEOLOGIA, 40., 1998. Belo Horizonte. Anais. Belo Horizonte: SBG, 1998. p. 17.

CAMPANHA, G. A. C.; SADOWSKI, G. R. Tectonics of southern portion of the Ribeira Belt (Apiaí Domain). Precambrian Research, v. 98, p. 31-51, 1999.

DAITX, E. C. Origem e evolução dos depósitos sulfetados tipo-perau ( $\mathrm{Pb}-\mathrm{Zn}-\mathrm{Ag})$, com base nas jazidas Canoas e Perau (Vale do Ribeira, PR). 1996. 435 f. Tese (Doutorado) - Instituto de Geociências, Universidade Estadual Paulista, Rio Claro.

DAITX, E. C. Prospecto de $\mathrm{Cu}, \mathrm{Pb}$ e $\mathrm{Zn}$ nas faixas carbonáticas Furnas/Lajeado, SP e PR. São Paulo: CPRM, 1980. 27 p. (Relatório interno).

DAITX, E. C.; BETTENCOURT, J. S.; ZANARDO, A. Metatufos traquíticos na área da Mina Perau (Vale do Ribeira, PR): significado geológico e importância na gênese dos corpos sulfetados (Pb-Zn-Cu-Ag-Ba). In: $\mathrm{CON}-$ GRESSO BRASILEIRO DE GEOLOGIA, 37., 1992. São Paulo. Boletim de Resumos. São Paulo: SBG, 1992. p. 255.

DAITX, E. C.; TEIXEIRA, W.; ZANARDO, A. Geologia e geocronologia do metagabro Apiaí, Vale do Ribeira, SP. In: CONGRESSOBRASILEIRODEGEOLOGIA, 36., 1990, Natal. Boletim de Resumos. Natal: SBG, 1990. p. 341.

FASSBINDER, E. A unidade Água Clara no contexto do Grupo Açungui: um modelo transpressivo de colisão oblíqua no Neoproterozóico paranaense. 1996. 207 f. Tese (Doutorado) - Instituto de Geociências, Universidade de São Paulo, São Paulo.

FIORI, A. P. Tectônica de cavalgamento no Grupo Açungui. In: SIMPÓSIO NACIONAL DE ESTUDOS TECTONICOS, 3., 1991. Rio Claro. Boletim de resumos... São Paulo: SBG, 1991.

FIORI, A. P. Tectônica e Estratigrafia do Grupo Açungui a Norte de Curitiba. 1990. 261 f. São Paulo. Tese (LivreDocência) - Instituto de Geociências da Universidade de São Paulo, São Paulo.

FIORI, A. P. Tectônica e estratigrafia do Grupo Açungui, PR. Boletim IG-USP. Série Científica, v. 23, p. 55-74, 1992.

FIORI, A. P.; GASPAR, L. A. Considerações sobre a estratigrafia do Grupo Açungui (Proterozóico Superior), Paraná, sul do Brasil. Boletim IG-USP. Série Científica, v. 24, p. 1-19, 1993.

FRASCÁ, M. H. B. O.; FIGUEIREDO, M. C. H.; ALMEIDA, M. A.;COUTINHO, J. M. V. Petrografia e geoquímica da Formação Água Clara, região de Araçaíba, SP. Boletim IG-USP. Série Científica, v. 21, p. 73-92, 1990.

FRASCÁ,M.H.B. O.; CAMPANHA, G.A. C.; FIGUEIREDO, M. C. H.; SADOWSKI, G. R. Geoquímica e ambiência tectônica de metabasitos do alto e médio Vale do Ribeira, São Paulo e Paraná. Revista Brasileira de Geociências, v. 27, n. 1, p. 41-48, 1997.

FRITZONS JÚNIOR, O.; PIEKARZ, G. F.; FALCADE, D. Geologia e potencial econômico do Grupo Setuva (PR). In: CONGRESSO BRASILEIRODE GEOLOGIA, 32., Salvador. Anais...Salvador: SBG, 1982. v. 3, p. 991-1001.

FUCK, R. A.; MARINI, O. J.; TREIN, E.; MURATORI, A. Geologia do leste Paranaense. In: CONGRESSO BRASILEIRO DE GEOLOGIA, 25., Rio de Janeiro. Anais... Rio de Janeiro: SBG, 1971, v. 5, p. 121-130.

FUCK, R. A.; MARINI, O. J.; TREIN, E. Mapa geológico preliminar do litoral, da Serra do Mar e Primeiro Planalto no Estado do Paraná. Boletim Paranaense de Geociências, v. 27, p. 123-152, 1969.

HACKSPACHER, P. C.; DANTAS, E. L.; SPOLADORE, A.; FETTER, A. H.; OLIVEIRA, M. A. F. Evidence of Neoproteozoic backarck basin development in the central Ribeira belt, southeastern Brazil: new geochronological and geochemical constraints from the São Roque - Açungui Groups. Revista Brasileira de Geociências, v. 30, p. 110-114, 2000.

HACKSPACHER, P. C.; DANTAS, E. L.; VAN SCHUMUS, W. R.; FETTER, A. Terrenos exóticos na Faixa Ribeira, sim ou não? In: SIMPÓSIO REGIONAL DE GEOLOGIA, 5., 1997. São Paulo. Atas... São Paulo: SBG, 1997. p. 69-71.

HASUI, Y.. Novo modelo geológico do Vale do Ribeira. São Paulo: IPT, 1986. 67 p. (Relatório Interno).

MANIESI, V. Petrologia das rocha anfibolíticas das regiões de Adrianópolis, Campo Largo e Rio Branco do Sull PR. 1997. 215 f. Tese (Doutorado) - Instituto de Geociências, Universidade Paulista, Rio Claro.

MANIESI, V.; OLIVEIRA, M. A. F. Quimismo mineral e metamorfismo de anfibólios e sua relação com feições texturais nos corpos anfibolíticos de Adrianópolis e Campo largo/PR. In: CONGRESSO BRASILEIRO DE GEOLOGIA, 39., 1996. Salvador. Anais...Salvador: SBG, 1996. v. 2, p. 138-140.

MANIESI, V.; OLIVEIRA, M. A. F. Anfibolitos com afinidades dos basaltos de fundo oceânico: regiões de Adrianópolis e Campo Largo/PR. In: CONGRESSO BRASILEIRO DE GEOLOGIA, 40., 1998. Belo Horizonte. Anais...Belo Horizonte: SBG, 1998. p.456.

MARINI, O. J.; TREIN; E.; FUCK, R. A. 1967. O Grupo Açungui no estado do Paraná. In: BIGARELLA, J. J.; SALAMUNI, R.; PINTO, V. M. "Geologia do PréDevoniano e Intrusivas Subseqüentes da porção oriental do estado do Paraná". Boletim Paranaense de Geociências, n. 23-25, p. 43-104.

PIEKARZ, G. F. Reconhecimento de unidades correlacionáveis à sequiência mineralizada do Perau, Estado do Paraná. In: SIMPÓSIO REGIONAL DE GEOLO- 
GIA, 3., 1981. Curitiba. Atas... Curitiba: SBG, 1981. v. 1, p. $148-154$.

PONTES, J. B. Geologia e potencialidades econômicas da Formação Água Clara - Paraná. Relatório interno da MINEROPAR, 1981.

PONTES, J. B. Geologia e potencialidades econômicas da Formação Água Clara - Paraná. In: CONGRESSO BRASILEIRO DE GEOLOGIA, 32., 1982. Salvador. Anais... Salvador: SBG, 1982. v. 3, p. 1002-1016.

REIS NETO, J. M. Faixa Itaiacoca: registro de uma colisão entre dois blocos continentais no neoproterozóico. 1994. 253 f. Tese (Doutorado) - Instituto de Geociências, Universidade de São Paulo, São Paulo.

SILVA, C. R.; TAKAHASHI, A. T.; CHIODI FILHO, C.; BATOLLA, F. Geologia e mineralização da região do Perau - Água Clara, Vale do Ribeira, PR. In: CONGRESSO BRASILEIRO DE GEOLOGIA, 32., 1982. Salvador. Anais... Salvador: SBG, 1982. v. 3, p. 1024-1036.

SILVA, M. J.; VASCONCELLOS, E. M. G. Estudo geoquímico das rochas metabásicas da faixa de dobramentos Apiaí. In: V CONGRESSO DE GEOQUÍMICADOS PAÍSES DE LÍNGUAPORTUGUESAEVII CONGRESSOBRASILEIRODE GEOQUÍMICA, 1999. Porto Seguro. Anais... Porto Seguro: 1999 , p. 592-595.

SOARES, P. C. Seqüiências tectono-sedimentares e tectônica deformadora no centro-oeste do Escudo Paranaense. In: SIMPÓSIO SUL BRASILEIRO DE GEOLOGIA, 3., 1987. Curitiba. Atas... Curitiba: SBG, 1987. p. 245-258.

SOARES, P. C.; ROSTIROLLA, S. P. Tectônica de escape tardicolisional nos Cinturões Ribeira e Dom Feliciano. In: SIMPÓSIO NACIONAL DE ESTUDOS TECTÔNICOS, 6., 1997. Pirinópolis. Anais... Pirenópolis: SBG, 1997. p. 65-68.

SPOLADORE, A. Caracterização da história deformacional das rochas proterozóicas da região de Bromado, Paraná. 1993. 157 f. Tese (Doutorado) - Instituto de Geociências, Universidade Estadual Paulista, Rio Claro.

TASSINARI, C. C. G.; BARBOUR, A. P.; DAITX, E. C.; $\mathrm{SATO}, \mathrm{K}$. Aplicação de isótopos de $\mathrm{Pb}$ e $\mathrm{Sr}$ na determinação da natureza das mineralizações de chumbo do Vale do Ribeira - São Paulo e Paraná. In: CONGRESSO BRASILEIRO DE GEOLOGIA, 36., 1990. Natal. Anais... Natal: SBG, 1990. v. 3, p. 1254-1266.

TASSINARI, C. C. G.; MELLO, I. S. C. A idade e a origem das mineralizações do granitóide de Itaoca. In: CONGRESSO BRASILEIRO DE GEOLOGIA, 38., 1994. Camboriu. Resumos Expandidos...Camboriu: SBG, 1994. p. 304-305.

VEIGA, H. R.; SALOMÃO, E. L. A formação São Sebastião e sua importância econômica. In: XXXI CONGRESSO BRASILEIRO DE GEOLOGIA, Balneário de Camboriu. Anais... Balneário de Camboriu: 1980. v. 2, p. 826-831.

WEBER, W.; SIGA JUNIOR, O.;BASEI, M. A. S.; SATO, K.
A Formação Água Clara na Região de Araçaíba -SP, Registro de uma bacia Mesoproterozóica. In: CONGRESSO BRASILEIRO DE GEOLOGIA, 41., 2002. João Pessoa. Anais...João Pessoa: SBG, 2002. p. 346.

WERNICK, E. Idade da tectônica de colocação do magmatismo granitóide Brasiliano do Estado de São Paulo e áreas adjacentes do Estado de Minas Gerais, SE Brasil. In: SIMPÓSIO REGIONAL DE GEOLOGIA, 5., 1997. São Paulo. Atas... São Paulo: SBG, 1997. v. 1, p. 104-106.

WINKLER, H. G. F. Petrogenesis of metamorphic rocks. Springer-Verlag, p. 348, 1977. 